\title{
Differential Expression of a $\beta$-1,4-Endoglucanase Induced by Diet Change in the Foliar Nematode Aphelenchoides fragariae
}

\author{
Zhen Fu, Paula Agudelo, and Christina E. Wells
}

First and second authors: School of Agricultural, Forest, and Environmental Sciences, 114 Long Hall, and third author: School of Agricultural, Forest, and Environmental Sciences, 168 Poole Agricultural Center, Clemson University, Clemson, SC 29634. Accepted for publication 27 April 2012.

\section{ABSTRACT}

Fu, Z., Agudelo, P., and Wells, C. E. 2012. Differential expression of a $\beta$ 1,4-endoglucanase induced by diet change in the foliar nematode Aphelenchoides fragariae. Phytopathology 102:804-811.

We identified and characterized a $\beta$-1,4-endoglucanase, Afr-ENG-1, in the foliar nematode Aphelenchoides fragariae that is differentially expressed when the nematode feeds on fungi or plants. When individuals from hosta plants were transferred to a fungus culture, expression of the enzyme decreased 1,812-fold after five generations on the fungus diet. Afr-eng-1 was readily detected in the genome of $75 \%$ of nematodes from the plant population but only in $38 \%$ of the diet-changed population. The gene cannot be detected in nematodes maintained on fungus for over 100 generations. Diet was also associated with changes in nematode body size and in the severity of symptoms caused on hosta leaves. Plant-diet nematodes caused larger lesions and were longer and thinner than fungusdiet nematodes. Nematodes moved from a plant diet to a fungus diet for five generations had the same body size as the nematodes that had fed on the fungus for 100 generations. Full-length sequences of Afr-eng-1 were obtained and found to encode a glycosyl hydrolase family 5 protein. This is the first $\beta-1,4$-endoglucanase and plant-parasitism-related gene described in the genus Aphelenchoides.

Additional keyword: cellulases.
The foliar nematode Aphelenchoides fragariae is an endo- and ectoparasite of aboveground parts of many plants. The nematode enters the leaf tissue through stomata or wounds, feeds on mesophyll cells (19), and causes characteristic vein-delimited lesions. The first line of defense that invading nematodes confront upon entering the leaf is the cell wall, of which cellulose is a primary component. In order to access the nutrient-rich cytoplasm, nematodes produce cell-wall-degrading enzymes to weaken the wall. The esophageal gland cells of plant-parasitic nematodes (PPN) have evolved to secrete cellulases, which are injected via the stylet into the plant tissue (2). Over the last decade, many PPN cell-wall-degrading enzymes have been identified and studied. Endo-1,4- $\beta$ glucanases (E.C 3.2.1.4), which degrade the $\beta-1,4$ linkage of cellulose, are some of the better characterized. The first glycosyl hydrolase family 5 (GHF5) genes reported in the animal kingdom were Gr-eng-1 and Gr-eng-2 from Globodera rostochiensis and $\mathrm{Hg}$-eng-1 and $\mathrm{Hg}$-eng-2 from Heterodera glycines (22). Other endoglucanases have been identified in root-knot nematode Meloidogyne incognita (17), stem and bulb nematode Ditylenchus africanus, lesion nematode Pratylenchus coffeae (11), and burrowing nematode Radopholus similis (6). Most of the GHF5 genes studied on PPNs correspond to obligate parasites of the superfamily Tylenchoidea.

Cellulases GHF 45 (9), GHF 16 (10), and GHF 5 (9) have been identified in pine wood nematode Bursaphelenchus xylophilus, which demonstrates the involvement of cellulases other than GHF 5 in facultative feeding strategies. A. fragariae is also a facultative plant parasite (i.e., having the ability to feed on both plants and fungi) of the same taxonomic family as B. xylophilus. Plant parasites in this family feed mainly on aerial parts of plants, and include pine wood nematode B. xylophilus, chrysanthemum foliar

Corresponding author: P. Agudelo; E-mail address: pagudel@clemson.edu

http://dx.doi.org/10.1094/PHYTO-12-11-0336

(c) 2012 The American Phytopathological Society nematode $A$. ritzemabosi, rice white tip nematode $A$. besseyi, and other economically important species.

Isolates of B. xylophilus that are more vigorous in the mycophagous phase have shown reduced virulence on pine (26). Likewise, we have observed differences in virulence between $A$. fragariae isolates reared on fungi versus plants (3). The mechanisms associated with feeding preferences and the factors that govern the coordination of the mycophagous and phytophagous behaviors in the life cycle of foliar nematodes have not been elucidated. It is likely that enzymatic changes regulated by gene expression underlie these feeding preferences and diet changes. Differential expression of $\beta$-1,4-endoglucanse genes has been shown on different developmental stages of PPNs $(4,6)$ but no research has been published on the differential expression of nematode cellulases under different diets.

The objectives of this study were to identify and characterize a $\beta$-1,4-endoglucanase in $A$. fragariae, determine the expression levels of this enzyme under plant and fungal diets, and examine phenotypic differences associated with different diets.

\section{MATERIALS AND METHODS}

Nematode materials. The nematodes used in this study were identified by morphology (21) as A. fragariae and labeled according to their diet: plant, fungus, and diet-changed. The fungus-diet (FD) nematodes are part of the Clemson University Nematode Collection and have been cultured in vitro on Cylindrocladium spp. grown in potato dextrose agar (PDA) (HiMedia Laboratories, India) under laboratory conditions for 25 years. The origin of the isolate is uncertain. The plant-diet (PD) nematodes were isolated from infected hosta plants in the South Carolina Botanical Garden, identified by morphology, and cultured on hosta plants in the field and the greenhouse since 2009. The diet-changed (DC) nematodes were obtained by transferring approximately 1,000 individuals from the PD nematodes to a fungal culture. For this, the nematodes were washed three times with $0.5 \%$ streptomycin 
sulfate (MP Biomedicals, OH), washed once with $0.5 \%$ chlorhexidine diacetate hydrate (Acros Organic, $\mathrm{NJ}$ ), and rinsed in sterilized tap water twice. Surface-sterilized nematodes were transferred to the Cylindrocladium sp. culture on PDA. The cultures were kept in an incubator at $25 \pm 2{ }^{\circ} \mathrm{C}$ for five generations, assuming a life cycle of 12 days. Prior to measurement and nucleic acid extraction, all nematodes were extracted from their cultures using the Baermann funnel technique (1).

DNA extraction and degenerate polymerase chain reaction. Genomic DNA of PD nematodes and FD nematodes was extracted from 20 individuals using the Sigma Extract-N-Amp kit (XNAT2) (Sigma-Aldrich, St. Louis). The manufacturer's protocol was modified by reducing all volumes to one-fourth of the recommended amounts. Twenty nematodes were placed into a $0.2-\mathrm{ml}$ centrifuge tube containing $25 \mu \mathrm{l}$ of the kit's extraction solution. The nematodes were crushed using the tip of a $<10-\mu l$ pipette tip, followed by addition of $7 \mu$ of the kit's tissue prep solution to the tube. The tube was then vortexed followed by a brief centrifugation to collect contents. The mix was then incubated at $55^{\circ} \mathrm{C}$ for $10 \mathrm{~min}$, followed by incubation at $95^{\circ} \mathrm{C}$ for $3 \mathrm{~min}$. Next, $25 \mu \mathrm{l}$ of the kit's neutralization solution was added to each tube and extracted DNA was used for polymerase chain reaction (PCR) or stored at $-20^{\circ} \mathrm{C}$. Amplification by PCR was conducted using $2 \mu \mathrm{l}$ of these DNA extracts and degenerate primers for nematode endoglucanases designed by Rosso et al. (17): Eng1: 5'-TAY GTI ATH GTI GAY TGG CA-3' and Eng2: 5'-GTI CCR TAY TCI GTI ACR AA- $3^{\prime}$. Reactions of $25 \mu$ l contained $1 \times$ ReadyMix Taq PCR Reaction Mix (Sigma-Aldrich): $50 \mathrm{mM} \mathrm{KCl,}$ $1.5 \mathrm{mM} \mathrm{MgCl}_{2}, 0.2 \mathrm{mM}$ dNTP, $0.2 \mu \mathrm{M}$ each primer, and 1.5 units of Taq DNA polymerase. PCR cycling parameters were initial denaturation of $94^{\circ} \mathrm{C}$ for $2 \mathrm{~min}$; followed by 35 cycles of $94^{\circ} \mathrm{C}$ for $30 \mathrm{~s}, 47^{\circ} \mathrm{C}$ for $1 \mathrm{~min}$, and $72^{\circ} \mathrm{C}$ for $2 \mathrm{~min}$; and a final extension at $72^{\circ} \mathrm{C}$ for $5 \mathrm{~min}$. PCR products were visualized on a $2 \%$ agarose gel stained with ethidium bromide. Amplicons were recovered from the gel using MinElute Gel Extraction Kit (Qiagen, MD) and sent to Clemson University Genomic Institute for sequencing. The sequence of the amplicon was verified to be an endoglucanase via blastn (http://blast.ncbi.nlm.nih.gov/Blast.cgi). Genespecific primers were designed based on the PD nematode amplicon sequence using Primer3 (18) to amplify a product of $186 \mathrm{bp}$.

RNA extraction and quantitative reverse-transcription PCR. Total RNA of 5,000 nematodes from each diet was extracted using an RNeasy mini kit (Qiagen). Total RNAs were treated with DNase I (Promega Corp., Madison, WI) at $37^{\circ} \mathrm{C}$ for $30 \mathrm{~min}$ and then at $65^{\circ} \mathrm{C}$ for $10 \mathrm{~min}$. Quantitative reverse-transcription (qRT)-PCR reactions were set up in $25 \mu$ following the instructions of the QuantiTect SYBR Green RT-PCR kit (Qiagen) on a Stratagene Mx3000P qRT-PCR system, using $0.5 \mu \mathrm{l}$ of the total RNA from the nematodes cultured on the three different diets as templates. qRT-PCR parameters included initial reverse transcription at $50^{\circ} \mathrm{C}$ for $30 \mathrm{~min}$; denaturation at $95^{\circ} \mathrm{C}$ for $15 \mathrm{~min}$; followed by 40 cycles of $94^{\circ} \mathrm{C}$ for $15 \mathrm{~s}, 50^{\circ} \mathrm{C}$ for $30 \mathrm{~s}$, and $72^{\circ} \mathrm{C}$ for $30 \mathrm{~s}$ (at the end of the this step, fluorescence data were collected). The dissociation curve (melting curve) was included at the end of the program from 55 to $95^{\circ} \mathrm{C}$. A portion of the $28 \mathrm{~S}$ ribosomal RNA gene (154 bp) was included for all samples as reference for normalization of products. The primers used in the qRT-PCR were Eng-F: 5'-GTT GAC GTT GCT GCT CAA AA3', Eng-R: 5'-CCG TAT TCG GTG ACG AAG AT-3', 28S-F: 5'AGT GGG ACA CTT GGT GTC TGT GA-3', and 28S-R: 5'TCT GAC TTC GTC CTG TTC GGG CA-3'. Four qRT-PCR reactions were included for each nematode diet and each gene. The standard curve method was used to quantify differences in expression. A dilution series for the PD nematode total RNA was used to create a standard curve for both the 28S gene and Afr-eng-1. Threshold $(\mathrm{Ct})$ values from each sample were converted to the relative copy number based on the standard curve, and the Afreng-1 expression fold changes between diets were calculated. The $28 \mathrm{~S}$ fold change was calculated the same way. The fold change of the endoglucanase gene corrected for the housekeeping gene was obtained by dividing the endoglucanase fold change by the $28 \mathrm{~S}$ gene fold change. All amplicons were treated with ExoSAP-IT (Affymetrix, Santa Clara, CA) and sequenced at Clemson University Genomic Institute.

Detection of Afr-eng from genomic DNA of single nematodes. Sixteen single nematodes from each diet (PD, FD, and DC) were hand picked into individual PCR tubes. Genomic DNA extraction was conducted as described above, following the manufacturer's instructions for the Extract-N-Amp Tissue PCR Kit (Sigma-Aldrich) and modifying to use one-tenth of the recommended volumes. Reactions were set as described above, using $2 \mu \mathrm{l}$ of the DNA extract from each individual and primers Eng-F and Eng-R for amplification of Afr-eng, and 28S-F and 28S-R for amplification of $28 \mathrm{~S}$ ribosomal gene as control for DNA extraction and PCR amplification. The PCR cycling param-

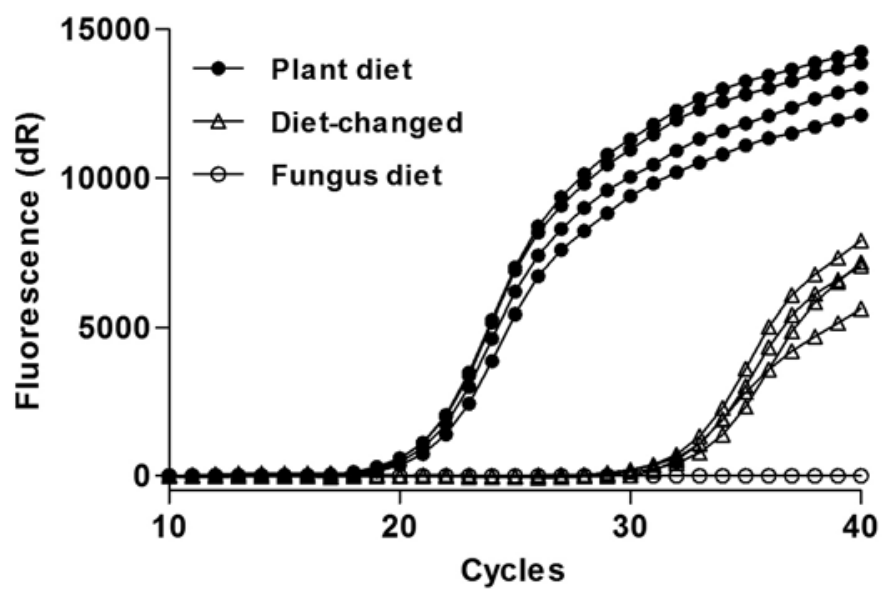

Fig. 1. Differential expression of Afr-eng-1 via quantitative reverse-transcription polymerase chain reaction (qRT-PCR) of plant-diet (PD), fungus-diet (FD), and diet-changed (DC) nematodes. No amplification was detected for FD nematodes. $\mathrm{X}$ axis: number of cycles, $\mathrm{Y}$ axis: fluorescence units. Each line represents one of four replicates. Replicates consisted of independent qRTPCR reactions for each RNA extraction. The fluorescence units versus number of cycles were plotted based on the raw amplification data. After normalization with $28 \mathrm{~S}$ ribosomal RNA gene expression, the expression of Afr-eng-1 of PD nematodes was 1,812 times higher than the DC nematodes.

TABLE 1. Homologs of the partial Afr-eng sequence identified in Aphelenchoides fragariae by degenerate polymerase chain reaction

\begin{tabular}{|c|c|c|c|c|}
\hline Species & Identity (\%) & Genes & E value & Accession \\
\hline Meloidogyne hapla & 71 & $\beta$-1,4-Endoglucanase & $1.00 \mathrm{E}^{-15}$ & AY277718.1 \\
\hline M. incognita & 71 & $\beta$-1,4-Endoglucanase (eng-6) & $1.00 \mathrm{E}^{-15}$ & AF323091.1 \\
\hline Ditylenchus africanus & 70 & Endoglucanase (engdel4) pseudogene & $5.00 \mathrm{E}^{-14}$ & GU139193.1 \\
\hline M. arenaria & 69 & $\beta$-1,4-Endoglucanase (eng-2) & $2.00 \mathrm{E}^{-12}$ & AF323098.1 \\
\hline M. javanica & 69 & $\beta$-1,4-Endoglucanase (eng-1) & $7.00 \mathrm{E}^{-12}$ & AF323099.1 \\
\hline Heterodera glycines & 70 & $\beta$-1,4-Endoglucanase- 1 precursor & $9.00 \mathrm{E}^{-11}$ & AF006052 \\
\hline Ditylenchus destructor & 66 & $\beta$-1,4-Endoglucanase & $4.00 \mathrm{E}^{-09}$ & FJ430142.1 \\
\hline Erwinia chrysanthemi & 66 & Extracellular endoglucanase & $3.00 \mathrm{E}^{-04}$ & Y00540.1 \\
\hline
\end{tabular}


eters were an initial denaturation at $94^{\circ} \mathrm{C}$ for $2 \mathrm{~min}$; followed by 45 cycles of $94^{\circ} \mathrm{C}$ for $30 \mathrm{~s}, 51^{\circ} \mathrm{C} 1 \mathrm{~min}$, and $72^{\circ} \mathrm{C}$ for $2 \mathrm{~min}$; and a final extension of $72^{\circ} \mathrm{C}$ for $5 \mathrm{~min}$. Products were visualized on a $2 \%$ agarose gel stained with ethidium bromide. The percentage of individuals bearing Afr-eng-1 with positive amplification was calculated. All amplicons were treated with ExoSAP-IT (Affymetrix, Santa Clara, CA) and sequenced at Clemson University Genomic Institute. Sequences were aligned using Bioedit (7).

Effect of diet on nematode body size. In total, 20 females and 20 males of each diet (PD, FD, and DC) were arbitrarily picked and mounted on microscope slides. A photo of each nematode was taken via ProgRes C5 (Jenoptik, Germany) connected to an Olympus BX 60 (Olympus, Japan) compound microscope. The body length and body width of each individual were measured using i-Solution (Focus Precision, Victoria, MN). Data on body length and body width for each diet were analyzed by one-way analysis of variance with JMP 9 (SAS Institute, Cary, NC). Significant differences in the mean body length and body width between nematode diets were determined by Tukey's honestly significantly difference test at $P<0.05$. The PD and FD nematodes had been cultured for $>100$ generations on their respective diets before measurement.

Afr-eng sequence analysis. Afr-eng gene sequences were obtained from an Illumina RNA-seq project of the foliar nematode carried out in our laboratory. The transcriptome was obtained from a mixture of life stages and diets. We established a local database with contigs assembled from 100-bp Illumina reads and queried the Afr-eng partial sequence amplified in the qRTPCR described above with tblastx algorithms. Three contigs showed high similarity $\left(E=2 \mathrm{e}^{-120}, E=2 \mathrm{e}^{-38}\right.$, and $\left.\mathrm{E}=\mathrm{e}^{-32}\right)$ to the Afr-eng partial sequence. The contigs were named Afr-eng-1, Afreng-2, and Afr-eng-3 and were submitted to GenBank (accession numbers JN851728, JN851727, and JQ768418, respectively). Sequences Afr-eng-2 and Afr-eng-3 were annotated as partial. The open reading frames (ORFs) of all three contigs were located with ORF Finder (http://www.ncbi.nlm.nih.gov/gorf/gorf.html). The
A
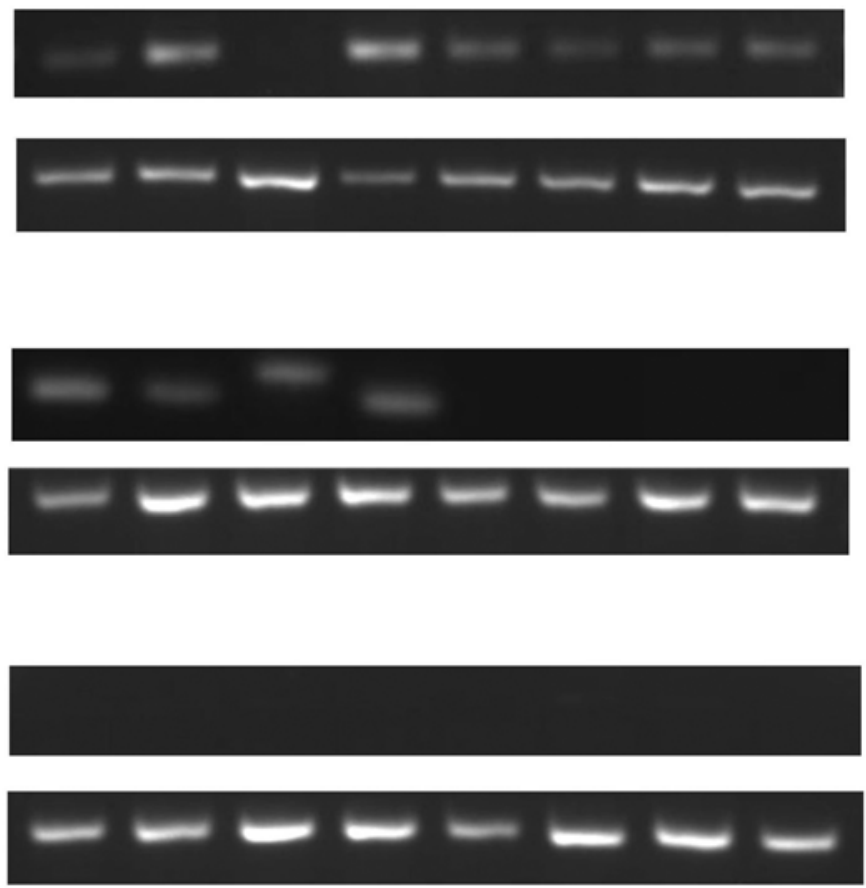

\section{Afr-eng-1}

Plant diet

28S

Afr-eng-1

Diet-changed

$28 S$

Afr-eng-1

\section{Fungus diet}

B

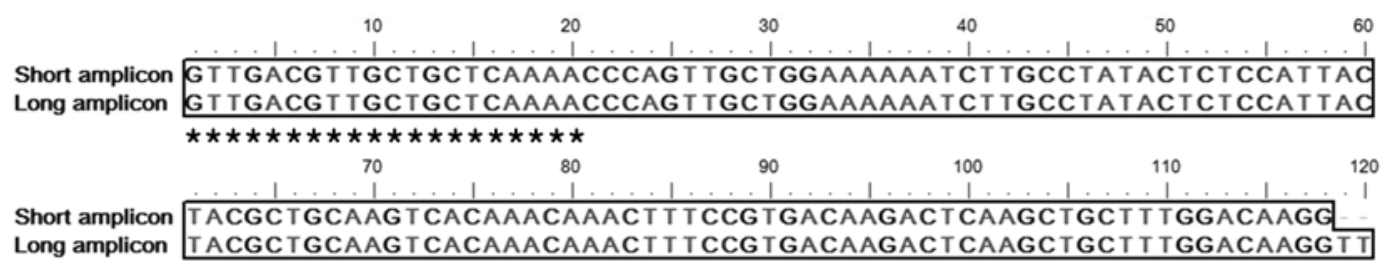

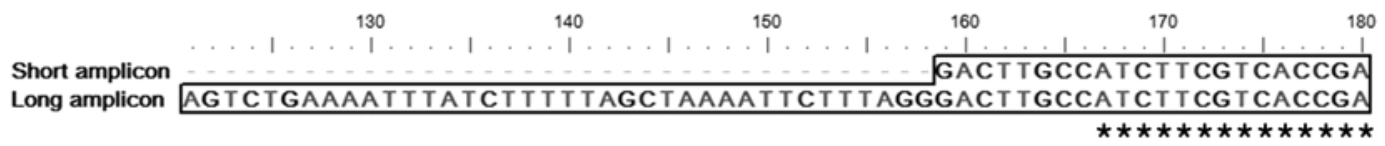

Short amplicon ATACGG

Long amplicon ATACGG

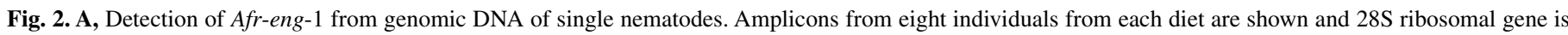

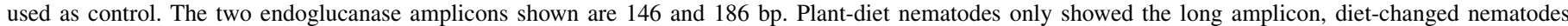

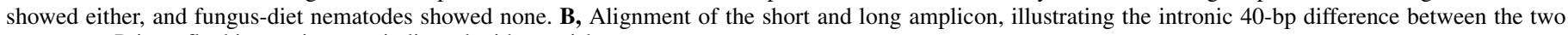
sequences. Primer flanking regions are indicated with asterisks. 
predicted proteins were queried through blastp to find homologous proteins from other PPNs. The signal peptide was predicted using SignalP 4.0 (16). The protein was searched through the Conserved Domains database of the National Center for Biotechnology Information (14) to find the domain and protein family. Two $\beta$-1,4-endoglucanase proteins, Pp-ENG (BAB68522) from $P$. penetrans and Rs-ENG (ABV54448) from $R$. similis, were aligned with Afr-ENG-1, Afr-ENG-2, and Afr-ENG-3 using ClustalW2 (12) and displayed in Jalview (25). Degenerate primer binding regions were located in the aligned protein sequences.

Cellulase sequences of PPNs were selected from GenBank and aligned using ClustalW2 (12). A maximum likelihood phylogenetic tree was constructed in PhyML using the LG amino acid substitution model and the SPR method of topology estimation (5). The reliability of the tree was assessed using 100 bootstrap replicates. The proteins used for the phylogenetic analysis and their corresponding GenBank Accession numbers were MiENG-1 (AAK21882), Mi-ENG-2 (AAK21883), Mi-ENG-3 (AAR37374), Hg-ENG-1 (AAC15707), Hg-ENG-2 (AAC15708), Hg-ENG-3 (AAC33860), Hg-ENG-4 (AAP88024), Hg-ENG-5 (AAP97436), Hs-ENG-1 (CAC12958), Hs-ENG-2 (CAC12959), Pp-Eng-1 (BAB68522), Pp-Eng-2 (BAB68523), Dd-ENG-1 (ACJ60676), Dd-ENG-2 (ACP20205), Da-ENG-1 (ABY52965), Bx-ENG-1 (AB179544.1), Bx-ENG-2 (AB179545.1), Bx-ENG-3 (AB179546.1), Aav-ENG-1 (AB495300.1), Aav-ENG-2 (AB495302.1), Rs-ENG-1 (ACB38289), Rs-ENG-2 (ABV54448), Rs-ENG-3 (ABV54449), and an outgroup Trichoderma sp. (M15665).

\section{RESULTS}

Identification of $\boldsymbol{A} \boldsymbol{f r}$-eng. No amplicons were detected in the FD nematodes using the degenerate primers, whereas one clear amplicon (450 bp) was detected in the PD nematodes. Blastn results showed high similarity between this amplicon and $M$. hapla $\beta$-1,4-endoglucanase, other PPN $\beta$-1,4-endoglucanases, and a bacterial cellulase from Erwinia chrysanthemi (Table 1).

Differential expression of $\boldsymbol{A}$ fr-eng-1 induced by diet change. The standard curves of 28S gene and Afr-eng-1 had $r^{2}$ values of 0.999 and 0.997 , respectively. The $28 \mathrm{~S}$ ribosomal gene was detected in all three diets and the dissociation curves for this amplicon were identical. Amplicons of Afr-eng-1 with identical dissociation curves were detected on the PD nematodes (average $\mathrm{Ct}$ of 22.05) and the DC nematodes (average Ct of 32.73) (Fig. 1). No amplicon was detected for the FD nematodes. Relative copy numbers were calculated based on the standard curves $(28 \mathrm{~S}$, $y=-3.827 \log x+1.41$ and Afr-eng-1, $y=-2.697 \log x+20.42)$. Expression of Afr-eng-1 was 1,812-fold higher in the PD nematodes than in the DC nematodes after the correction with housekeeping gene fold change.

Detection of $A$ fr-eng-1 in genomic DNA from single nematodes. The frequency of detection of Afr-eng-1 in individuals was different among the three diets (Fig. 2A). The gene was readily detected in $75 \%$ (12 of 16) of the individuals from the plant diet by amplifying a 186-bp portion of the gene. However, in the DC nematodes, the gene was detected in only $37.5 \%$ (6 of 16) of the individuals, and 4 of these 6 amplicons were 40 bp shorter (146 bp). The alignment of the short and long amplicons (Fig. 2B) shows the 40-bp intronic sequence responsible for the band shift on the gels. The gene was not amplified in any ( 0 of 16) of the individuals from the FD.

Effect of diet change on body size. There were significant differences $(P<0.05)$ between the PD nematodes and the FD nematodes in the body length and body width of females and males (Fig. 3). The females of the PD nematodes were longer (average $690 \mu \mathrm{m}$ ) and thinner (average $17.0 \mu \mathrm{m}$ ) than females of the FD nematodes. The FD females were an average of $609 \mu \mathrm{m}$ long and $20 \mu \mathrm{m}$ wide, and the DC females were an average of $643 \mu \mathrm{m}$ long and $22.3 \mu \mathrm{m}$ wide. There were no differences in the body length for the males but males from the PD were sig-
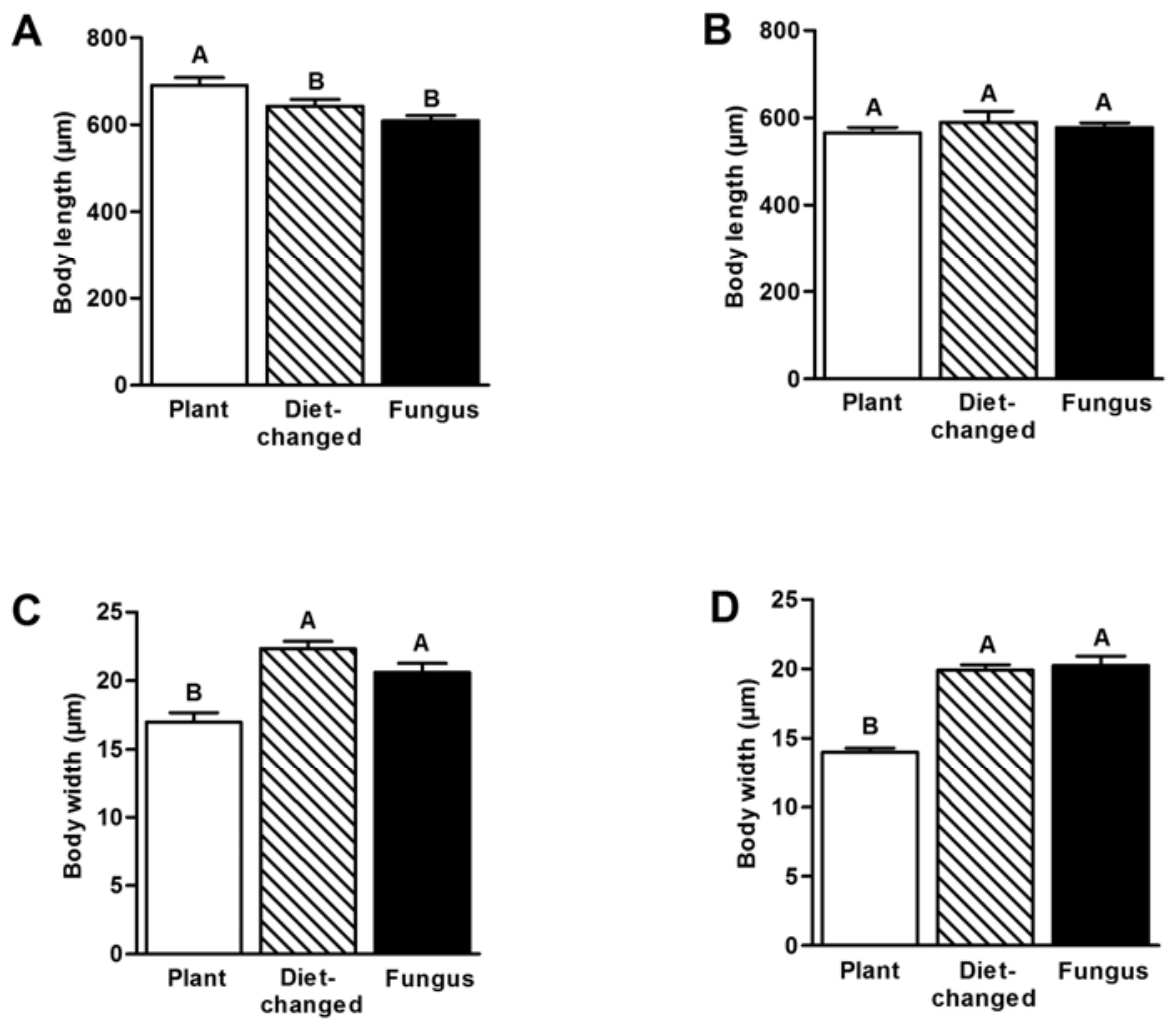

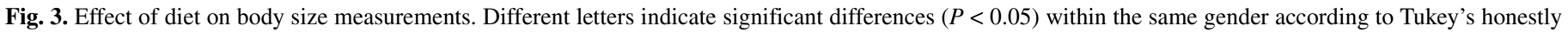

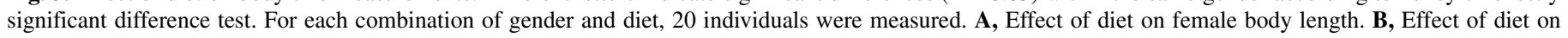
male body length. C, Effect of diet on female body width. D, Effect of diet on male body width. Error bars indicate the standard error. 
nificantly $(P<0.05)$ thinner (average $13.99 \mu \mathrm{m})$ than the FD males (average $20.2 \mu \mathrm{m})$ and the DC males (19.9 $\mu \mathrm{m}$ average). There were no differences $(P<0.05)$ in the body measurements for males or females between the FD and the DC. The DC nematodes have the same origin as the PD nematodes but, after five generations of feeding on the fungus, their appearance resembles that of the FD nematodes and is different from the parent population.

Characterization Afr-eng-1. Of the three putative endoglucanases identified (Afr-eng-1, Afr-eng-2, and Afr-eng-3), only Afreng-1 aligned perfectly with the partial Afr-eng sequence amplified via qRT-PCR (Fig. 4), confirming that this is the sequence

A

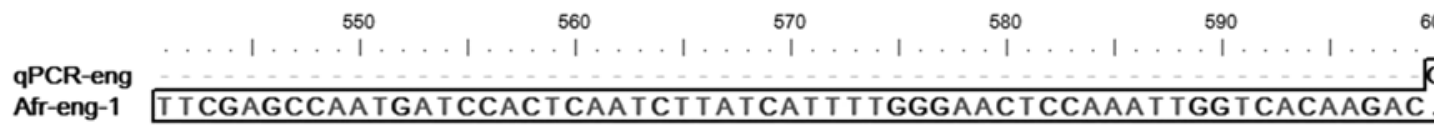

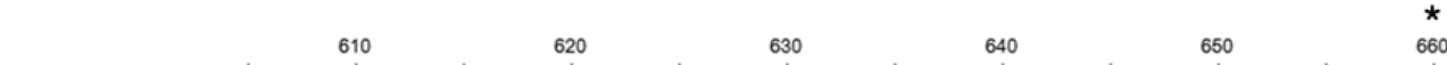
qPCR-eng TTGACGTTGCTGCTCAAAATCCAGTTGCTGGAAAAAATCTTGCCTATACTCTCCATTACT

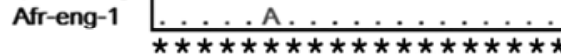

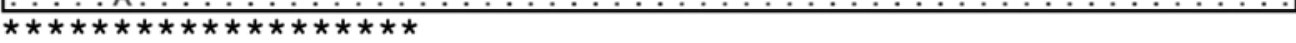

$\begin{array}{rrrrrr}670 & 680 & 690 & 700 & 710 & 720\end{array}$

qPCR-eng ACGCTGCAAGTCACAAACAAGCTCTTCGTGACAAGACTCAAGCTGCTT I

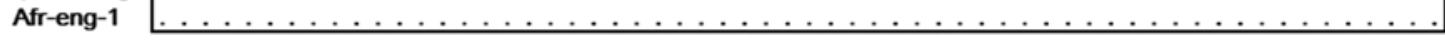

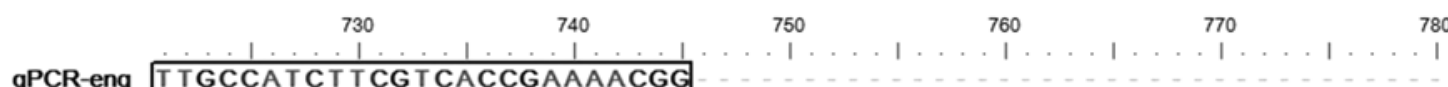

Afr-eng-1 ......... T. . . . . . AACTGTTGATGCT TCTGGCGGCGGCAGTGTCGACG

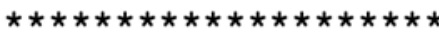

B

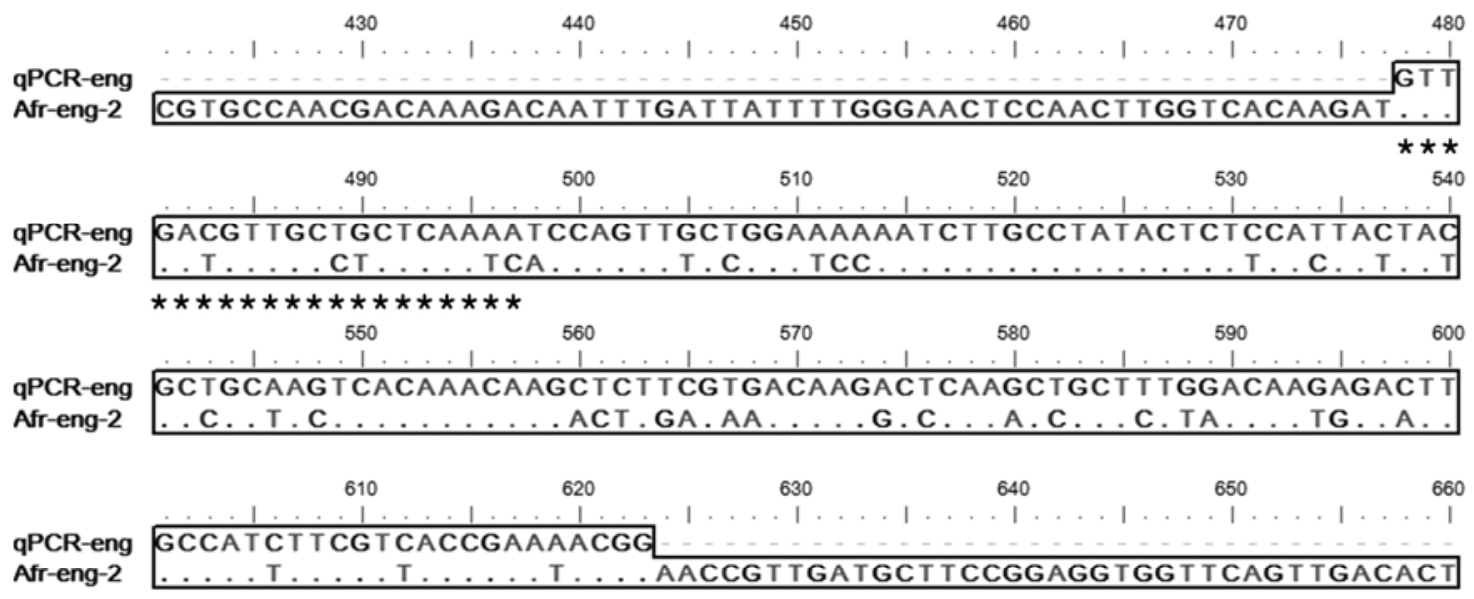

C

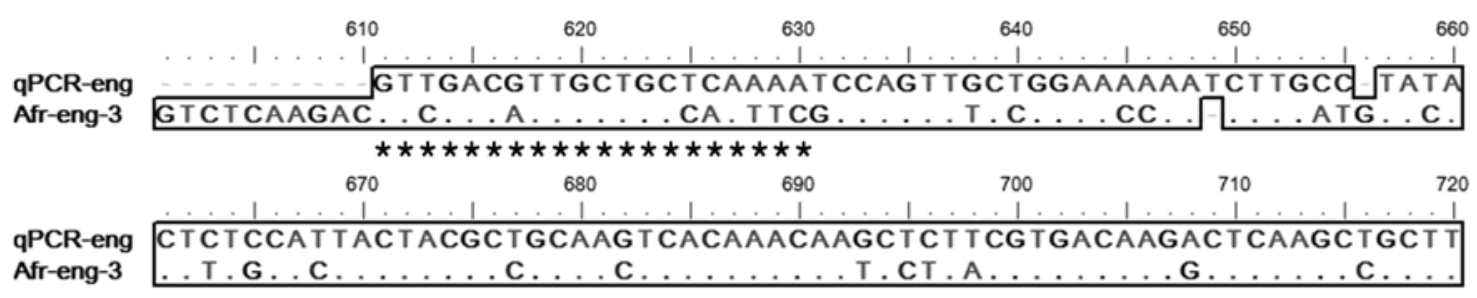

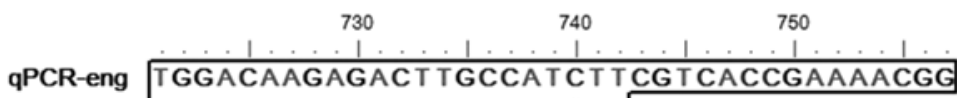

Afr-eng-3 .A.....G.GA...... . . .

Fig. 4. Sequence alignment of quantitative reverse-transcription polymerase chain reaction (qRT-PCR) partial endoglucanase with de novo assembled A, Afr-eng-1; B, Afr-eng-2; and C, Afr-eng-3 from the transcriptome of Aphelenchoides fragariae. Gene-specific primers Eng-F and Eng-R designed from product of degenerate PCR were used in the qRT-PCR and marked as asterisks. The qRT-PCR sequence has the highest similarity with Afr-eng-1. Mismatched sequences in the assembled contigs are labeled as nucleotide letters. 
being amplified and differentially expressed. When mapping the short reads generated by Illumina to Afr-eng-1, the abundance of reads for the PD nematodes was 17,714 , whereas the abundance of reads for the DC nematodes was 1.57 , based on the calculation of RSEM (http://deweylab.biostat.wisc.edu/rsem/). Afr-eng-1 encodes for a 320-amino-acid (aa) protein, and its signal peptide (1 to 17 aa), GHF 5 domain (33 to 278 aa), and predicted active sites (positions 152 and 239) are shown in Figure 5.

Blast results indicate that all three putative proteins are homologous to other PPN $\beta$-1,4-endoglucanases: $R$. similis RsENG (ABV54446; E = 1 $\mathrm{e}^{-154}$ ), $P$. coffeae Pc-ENG (ABX79356; $\left.\mathrm{E}=4 \mathrm{e}^{-150}\right)$, P. penetrans $\mathrm{Pp}-\mathrm{ENG}\left(\mathrm{BAB} 68522 ; \mathrm{E}=3 \mathrm{e}^{-148}\right)$, and $M$. incognita Mi-ENG (AAD45868.1; $\mathrm{E}=4 \mathrm{e}^{-135}$ ). The alignment of two representative sequences from other plant nematodes with the three predicted endoglucanases is shown in Figure 6.
Phylogenetic analysis. A maximum likelihood tree, condensed with cut-off value of $50 \%$ from the bootstrap consensus tree, is shown in Figure 7. Afr-ENG-1, Afr-ENG-2, and Afr-ENG-3 form a tight cluster and were placed in a large clade with Pratylenchus, Meloidogyne, Aphelenchus, Heterodera, Radopholus, and Ditylenchus endoglucanases. The $B$. xylophilus $\beta$-1,4-endoglucanases: Bx-ENG-1 and Bx-ENG-2 formed a clade separate from all other PPN $\beta$-1,4-endoglucanases examined in this study.

\section{DISCUSSION}

Plant-parasitic nematodes require anatomical specializations (e.g., the stylet) and an arsenal of gene products to accomplish plant parasitism. Several of these genes are involved in cell-wall degradation, necessary for penetration and migration through the

\title{
MIQVAAVLFVFIGFANAVAPPYGQLSVKGNKILGADGKPVALHGMSLF'WSQWGEGAPFYNKDTVQALKCS 70 \begin{tabular}{|c|c|}
\hline Signal peptide & Glycosyl hydrolase family 5
\end{tabular}
}

\begin{abstract}
WNANLVRAAMGVEEGGYLTNQATEQGKLEAVVKAAIDLGIYVIIDWHDHHAYQHPDKAVEFFSAMSKKYA 140 Glycosyl hydrolase family 5 GVPNIIYEIFNEPLSVSWTSDLVPYHNKVISAIRANDPLNLIILGTPNWSQDVDIAAQNPVAGKNLAYTL 210 Glycosyl hydrolase family 5

HYYAASHKQALRDKTQAALDKRLAIFVTEYGTVDASGGGSVDVQSSNEWWAFLDANKISYANWAIGNKAE 280 Glycosyl hydrolase family 5
\end{abstract}

\section{AAAALTPGTTAQQVGDDSRLTASGKLVKQKLKSQNNGVSC}

Fig. 5. Predicted sequence of putative endoglucanase Afr-ENG-1 (GenBank accession number JN851728). The signal peptide is indicated by the big arrow (position 1 to 17), the glycosyl hydrolase family 5 is highlighted (position 33 to 278), and the predicted active sites are indicated by the small arrows (positions 152 and 239)

\begin{abstract}
Afr-ENG-1/1-320....... MI QVAAVLFVF I GFANAVAPPYGQL SVKGNKILGADGKPVALHGMSLFWSQWGEGAPFYNKDTVQALKC SWN 72

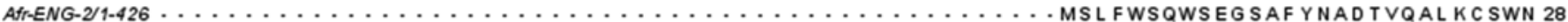
Afr-ENG-3/1-236.......MALLQLAALL SAF VVMT NAVAPPYGQL SVKGSKLLGSNGQEVALHGMSLFWSQWSEGSVFYNKDTVQALKC SWN 74 Pp-Eng/1-455 MTSSSSSMALLVL CLLPLQFFLVVLAADPPYGQLKVSGGKLVGSNGQAVALHGMSLFWSSFSEGSPFYTADVVKQLKC SWN 81 RSEng/1-319 ........ML SLFLLPL.FFAFASAANPPYGQLSVSGTKLKGSSGQDVALHGMSLFWSNFGEGAPFYNAATVKALKCKWN 71 Eng1

Afr-ENG-1/1-320 ANL VRAAMGVEEG - G YL TNQATEQGKLEAVVKAA I DL G IYVIIDWHDHHAYQHPDKAVEFFSAMSKKYAGVPN I I YE I F NE 152 Afr-ENG-2/1-426 ANL VRAAMGVEEG - GYLTNPSGEQAKLEAVVEAAISAG IYVI I DWHDHNAASHTDKAVEFFSAISKKYAGNPNI I YEVFNE 108 Afr-ENG-3/1-236 ANVVRAAMG VEEG - GYLTNPTAEQAKVETVVQAAIDLG IYVI I DWHDHNAHYHTDKAVQFFSAISKKYAGVPNVL YEI YNE 154 Pp-Eng/1-455 ANL VRAAMGVEEGSGYLSNKQGQMSMVETVI KAAIAEG I YVLVDWHDHNAQNHQSQAIEFFTYIAKTYGNNPHIIYETFNE 162 RaEng/1-319 SNIVRAAMGVEGG . YLNNPSQEQAKLEAVVQAAIAEG IYVIIDWHDHNAQSHQSQAVSFFTAMSKKYGKNTNILYEIFNE 150

Afr-ENG-1/1-320 PL SVSWT SDLVPYHNKVISAIRANDPLNL I ILGTPNWSQDVDIAAQNPVAG-KNLAYTLHYYAASHKQALRDKTQAALDKR 232 Afr-ENG-2/1-426 PLQVSWTDVLKPYHTAVVNAIRANDKDNLIILGTPTWSQDVDVASQSPVSG.SNLAYTLHYYAATHKQDLRNKAQTALNNG 188 Afr-ENG-3/1-236 PLQVPWTD- LKPYHTAVINAIRANDKNNVIILGTP TWSQDVDIAANSPVSG. TNLMYTLHYYAATHKQSLRDKAQAALNKG 233 Pp-Eng/1-455 PLQVDWG - VVKPYHVAVVAAIRASDPDNVIVLGTPTWSQDVDVAATNPVSG. TNLCYTMHYYAATHKQSLRDKTQAALNKG 241 RSEng/1-319 PLQVDWNSVVKPYAQAVIKAIRANDAKNVIIVGTPTWSQDVDVAANSPITGQKNIMYTLHYYAATHKQDLRNKLTTAVNKG 231 Eng2

Afr-ENG-1/1-320 LA I FVTEYGTVDASGGGSVDVQSSNEWWAFLDANKISYANWAIGNKAEAAAALTPGTTAQQVGDDSRLTASGKLVKQKLKS 313 Afr-ENG-2/1-426 I A I FVTEYG TVDASGGGSVDTQSSNDWWTFLDNNKISYANWA I DNKAEAAAALTPG T TAQQVGDDSRLTQSGQLVKNKL KG 269

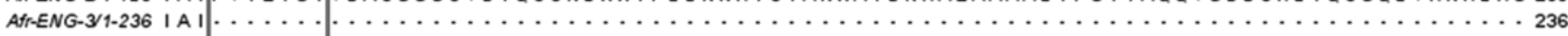
Pp-Eng/1-455 VCVFVTEYGTVSADGNGGMDQASSNEWYTFLDNNKISYANWAVDAKSESSAALNPGTQPSQISSDSVLTASGSFVKAKLKS 322 RsEng/1-319 LPVFVTEYGTVTADGNGYVDAAESKTWWNFLDGLKISYVNWAIDNKDEKSAALTPGTSSSQVGDSSRWTESGKLVQAKLAS 312
\end{abstract}

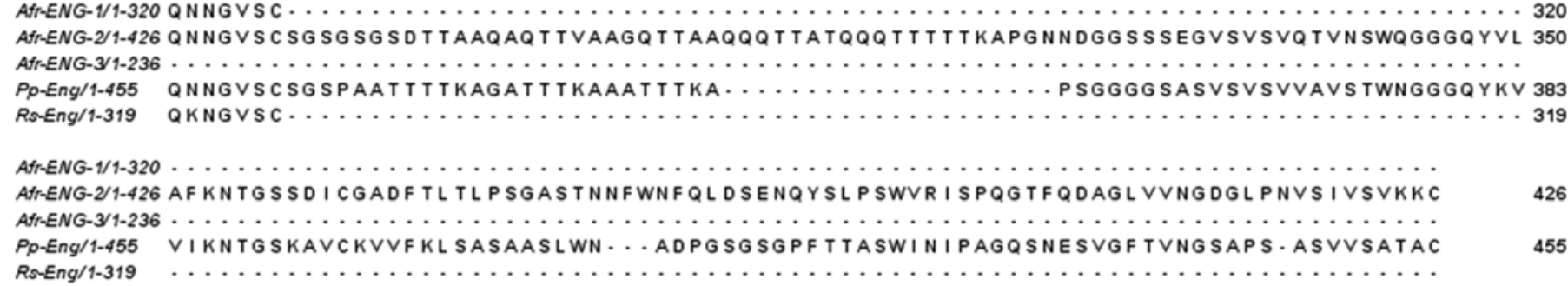

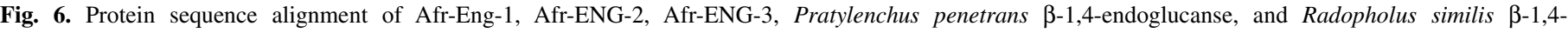
endoglucanase. Degenerate primer binding regions are marked. 
plant tissue. A number of cellulases have been identified as essential to plant parasitism in PPNs, mostly in sedentary and rootparasitic nematodes. Only a few non-root-parasitic PPN cellulases have been studied, including endoglucanases from $D$. africanus (11) and B. xylophilus (9). Different GHF proteins (GHF 16 and GHF 45) were identified in B. xylophilus $(9,10)$. As a closely related species to $B$. xylophilus, A. fragariae shares many similarities with B. xylophilus, especially morphological features and facultative plant parasitism. In this work, we report and characterize the first cellulase gene identified in the genus Aphelenchoides. Interestingly, based on local alignment results, Afr-eng shares more similarities with endoglucanases from Meloidogyne, Radopholus, and Pratylenchus spp. than with those from Bursaphelenchus spp. However, if we consider habitat and niche, the habitat of B. xylophilus (wood tissue) would require a different set of adaptations and could explain why the foliar habit may be closer to the root habit in terms of the necessary cellulases. Cellulases from families other than GHF 5 have not yet been identified from Aphelenchoides spp. but we would expect the facultative feeding strategies of A. fragariae to render other enzymes necessary to degrade the fungal cell wall. For example, Kikuchi et al. (10) hypothesize that endo-1,3- $\beta$-endoglucanase has a role in facultative fungal feeding of B. xylophilus, because $\beta$-1,3-glucan is a main component of fungal cell walls.

No genomic PCR amplicons were detected in the FD nematodes using degenerate primers Eng1 and Eng2. These primers encode amino acid sequences YVIVDWH and FVTEYGT, respectively (17), in the catalytic domain, two short amino acid sequences highly conserved in many PPN species. We were able to locate those two amino acid sequences in the predicted AfrENG (Fig. 6). We also did not detect any amplicon from the FD nematodes via qRT-PCR. The lower detection in the DC nematodes and the lack of detection in the FD nematodes suggest selection against the portion of the population in which this gene

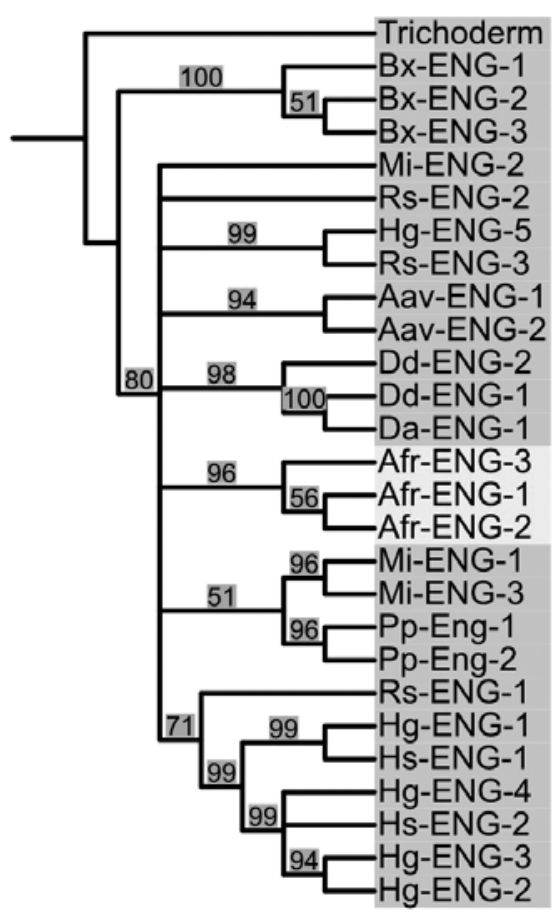

Fig. 7. Phylogenetic relationships among selected nematode endoglucanases. The tree was constructed by comparisons of the endoglucanases listed in the Materials and Methods, using maximum likelihood of PhylML. Numbers next to the branches indicate the bootstrap value. Trichoderma is the outgroup. Abbreviations: Mi: Meloidogyne incognita; Pp: Pratylenchus penetrans; Afr: Aphelenchoides fragariae; Dd: Ditylenchus destructor; Da: Ditylenchus africanus; Rs: Radopholus similis; Hg: Heterodera glycines; Hs: Heterodera schachtii; Aav: Aphelenchus avenae; Bx: Bursaphelenchus xylophilus. is readily detectable. In the original PD nematodes, the frequency of the individuals in which the gene is readily detectable is high (75\%) and the amplicon includes a 40-bp intron present in only some of the amplicons of the DC nematodes. It is possible that alternative splicing of the Afr-eng-1 is responsible for this amplicon size difference but further sequencing of each individual is necessary to test this hypothesis. The portion of the population for which the gene cannot be detected by the method we employed increased as the diet shifted to fungus. This could be caused by variation in copy number, polymorphisms, or a reason yet to be determined by further studies.

In other studies, $\beta$-1,4-endoglucanases from pinewood nematodes, B. xylophilus, have been isolated from cultures maintained on fungi $(9,13)$. These nematodes were originally isolated from trees and then maintained on the fungus Botrytis cinerea for easy manipulation. It is possible that they had not completely adapted to the FD or that these endoglucanases are not as inducible as the ones we report. Based on the qRT-PCR analysis, we detected a large decrease in Afr-eng-1 expression in the DC nematodes compared with the PD nematodes. Additionally, fewer individuals in the population were detected bearing Afr-eng after the diet shift from plant to the fungus, which suggests selection acting on the population (23).

Some researchers have proposed that PPN endoglucanase genes may have been acquired horizontally from bacteria $(8,28)$, due to the high similarity of the endoglucanases found in PPNs and prokaryotes. Nonetheless, there is no experimental evidence to support such an origin of PPN endoglucanase genes. It is also possible that the endoglucanases in the PPN are produced by symbionts, as is the case with other nematodes (20), and that the diet change impacts the community composition or population of these symbionts; however, this has not been demonstrated either.

We observed two phenotypic changes associated with diet changes: altered symptom severity and altered body size. In greenhouse studies (3), using four different hosta cultivars, we observed differences $(P<0.05)$ in the severity of symptoms caused by foliar nematodes maintained on the fungus (leaf area affected of 1.21 to $4.13 \%$ ) and by those maintained on the plants (leaf area affected of 4.17 to $25.95 \%$ ). Nematodes maintained on plants for $>100$ generations also had higher reproduction on the hosta cultivars evaluated. These observations are consistent with the expression profiles of Afr-eng in the PD nematodes and FD nematodes and indicate the potential role of this enzyme in penetration and migration. Availability of nutrients, especially of nitrogen, in plants is a limiting factor for herbivores (15). Plantparasitic nematode body size tends to decrease at lower nutrient availability (24). The different sources and availability of nitrogen in fungal and plant diets may explain the changes in body size. It is difficult to determine which diet source provides higher nutrients because one diet produced longer and thinner individuals while the other produced shorter but wider adults. Body size, in this case, could be more likely associated with movement and feeding behavior. Feeding on plants, especially as an endoparasite, arguably would benefit from a thinner figure and would require more energy than ectoparasitic feeding on fungi.

There is evidence of endoglucanases acting as parasitism genes during the penetration and migration events of the infection process. Differential expression of endoglucanases has been observed in different life stages of PPNs: low expression of endoglucanases has been found in J3, J4, and sedentary females of reniform nematodes (27) and in all noninfective stages of root-knot and cyst nematodes $(4,6)$. In the case of foliar nematodes, all the life stages are infective and all the developmental stages move and feed on plant tissue. We have found that expression levels of endoglucanases are relevant to symptom severity.

Endoglucanases play an important role in the host-parasite relationships of foliar nematodes and plants. Our studies suggest that they may be significant pathogenicity factors. More studies 
are necessary to identify the involvement of different endoglucanases and how they participate in regulating the phytophagous and mycophagous behaviors of these nematodes.

\section{ACKNOWLEDGMENTS}

We acknowledge the support of Clemson University Research Investment Initiative Fund Program and thank S. Scott, J. Kerrigan, and A. Abbott in Clemson University for sharing their research facilities.

\section{LITERATURE CITED}

1. Baermann, G. 1917. Eine einfache Methode zur Auffindung von Ancylostomum (Nematoden) Larven in Erdproben. Geneeskd. Tijdschr. Ned. Indie 57.

2. Davis, E. L., Hussey, R. S., and Baum, T. J. 2004. Getting to the roots of parasitism by nematodes. Trends Parasitol. 20:134-141.

3. Fu, Z., Gerard, P., and Agudelo, P. 2012. A protocol for assessing resistance to Aphelenchoides fragariae in hosta cultivars. Plant Dis. (In press.)

4. Goellner, M., Smant, G., Boer, J. M. D., Baum, T. J., and Davis, E. L. 2000. Isolation of beta-1,4-endoglucanase genes from Globodera tabacum and their expression during parasitism. J. Nematol. 32:154-165.

5. Guindon, S., Dufayard, J. F., Lefort, V., Anisimova, M., Hordijk, W., and Gascuel, O. 2010. New algorithms and methods to estimate maximumlikelihood phylogenies: Assessing the performance of PhyML 3.0. Syst. Biol. 59:307-321.

6. Haegeman, A., Jacob. J., Vanholme, B., Kyndt, T., and Gheysen, G. 2008. A family of GHF5 endo-1,4-beta-glucanases in the migratory plantparasitic nematode Radopholus similis. Plant Pathol. 57:581-590.

7. Hall, T. A. 1999. BioEdit: a user-friendly biological sequence alignment editor and analysis program for Windows 95/98/NT. Nucleic Acids. Symp. Ser. 41:95-98.

8. Jones, J. T., Furlanetto, C., and Kikuchi, T. 2005. Horizontal gene transfer from bacteria and fungi as a driving force in the evolution of plant parasitism in nematodes. Nematology 7:641-646.

9. Kikuchi, T., Jones, J. T., Aikawa, T., Kosaka, H., and Ogura, N. 2004. A family of glycosyl hydrolase family 45 cellulases from the pine wood nematode Bursaphelenchus xylophilus. FEBS Lett. 572:201-205.

10. Kikuchi, T., Shibuya, H., and Jones, J. T. 2005. Molecular and biochemical characterization of an endo- $\beta$-1,3-glucanase from the pinewood nematode Bursaphelenchus xylophilus acquired by horizontal gene transfer from bacteria. Biochem. J. 389:117-125.

11. Kyndt, T., Haegeman, A., and Gheysen, G. 2008. Evolution of GHF5 endoglucanase gene structure in plant-parasitic nematodes: No evidence for an early domain shuffling event. BMC Evol. Biol. 8:305.

12. Larkin, M. A., Blackshields, G., Brown, N. P., Chenna, R., McGettigan, P. A., McWilliam, H., Valentin, F., Wallace, I. M, Wilm, A., Lopez, R., et al. 2007. Clustal W and Clustal X version 2.0. Bioinformatics 23:2947-2948.

13. Ma, H. B., Lu, Q., Liang, J., and Zhang, X. Y. 2011. Functional analysis of the cellulose gene of the pine wood nematode, Bursaphelenchus xylophilus, using RNA interference. Genet. Mol. Res. 10:1931-1941.

14. Marchler-Bauer, A., Lu, S., Anderson, J. B., Chitsaz, F., Derbyshire, M. K., DeWeese-Scott, C., Fong, J. H., Geer, L. Y., Geer, R. C., Gonzales, N. R., et al. 2011. CDD: A conserved domain database for the functional annotation of proteins. Nucleic Acids Res. 39:225-229.

15. Mattson, W. J. 1980. Herbivory in relation to plant nitrogen content. Annu. Rev. Ecol. Syst. 11:119-161.

16. Petersen, T. N., Brunak, S., von Heijne, G., and Nielsen, H. SignalP 4.0: discriminating signal peptides from transmembrane regions. Nat. Methods. 2011. 8:785-786.

17. Rosso, M.-N., Favery, B., Piotte, C., Arthaud, L., Boer, J. M. D., Hussey, R. S., Bakker, J., Baum, T. J., and Abad, P. 1999. Isolation of a cDNA encoding a beta-1,4-endoglucanase in the root-knot nematode Meloidogyne incognita and expression analysis during plant parasitism. Mol. Plant-Microbe Interact. 12:585-591.

18. Rozen, S., and Skaletsky, H. 2000. Primer3 on the WWW for general users and for biologist programmers. Methods Mol. Biol.132:365-386.

19. Sanwal, K. C. 1959. A simple method for rearing pure populations of the foliar nematode, Aphelenchoides ritzembosi, in the laboratory. Can. J. Zool. 37:707-711.

20. Sicard, M., Ferdy, J. B., Pagès, S., Le Brun, N,. Godelle, B., Boemare, N., and Moulia, C. 2004. When mutualists are pathogens: An experimental study of the symbioses between Steinernema (entomopathogenic nematodes) and Xenorhabdus (bacteria). J. Evol. Biol. 17:985-993.

21. Siddiqi, M. R. 1975. Aphelenchoides fragariae. CIH Description of PlantParasitic Nematodes Set 5, No. 74.

22. Smant, G., Stokkermans, J. P., Yan, Y., de Boer, J. M., Baum, T. J., Wang, X., Hussey, R. S., Gommers, F. J., Henrissat, B., Davis, E. L., et al. 1998. Endogenous cellulases in animals: Isolation of beta-1, 4-endoglucanase genes from two species of plant-parasitic cyst nematodes. Proc. Natl. Acad. Sci. USA 95:4906-4911.

23. Sved, J. A. 1968. Possible rates of gene substitution in evolution. Am. Nat. 102:283-293.

24. Verschoor, B. C., de Goede, R. G. M., de Vries, F. W., and Brussaard, L. 2001. Changes in the composition of the plant-feeding nematode community in grasslands after cessation of fertiliser application. Appl. Soil Ecol. 17:1-17.

25. Waterhouse, A. M., Procterm J. B., Martin, D. M., Clamp, M., Barton, G. J. 2009. Jalview version 2-a multiple sequence alignment editor and analysis workbench. Bioinformatics 25:1189-1191.

26. Wingfield, M. J. 1987. A comparison of the mycophagous and phytophagous phases of the pine wood nematode. Pages 81-90 in: Pathogenicity of the Pine Wood Nematodes. M. J. Wingfield, ed. American Phytopathological Society, St. Paul, MN.

27. Wubben, M. J., Ganji, S., and Callahan, F. E. 2010. Identification and molecular characterization of a beta-1.4-endoglucanse gene (Rr-eng-1) from Rotylenchulus reniformis. J. Nematol. 42:342-351.

28. Yan, Y., Smant, G., Stokkermans, J., Qin, L., Helder, J., Baum, T., Schots, A., and Davis, E. 1998. Genomic organization of four beta-1,4-endoglucanase genes in plant-parasitic cyst nematodes and its evolutionary implications. Gene 220:61-70. 